\title{
Fluorophilicity Switch by Solvation
}

\author{
Akihiro Orita, Sumiyo Man-e, Junzo Otera* \\ Department of Applied Chemistry, Okayama University of Science, Ridai-cho, \\ Okayama 700-005, Japan
}

\section{Supporting Information}

General: All reactions were carried out under an atmosphere of argon with freshly distilled solvents, unless otherwise noted. Tetrahydrofuran (THF) was distilled from sodium/benzophenone. Acetonitrile was distilled from $\mathrm{CaH}_{2}$. Silica gel (Daiso gel IR60) was used for column chromatography. NMR spectra were recorded at $25{ }^{\circ} \mathrm{C}$ on JEOL Lambda 300 and JEOL Lambda 500 instruments and calibrated with tetramethylsilane (TMS) as an internal reference, and tetramethylstannane $\left(\mathrm{Me}_{4} \mathrm{Sn}\right)$ and pentafluorobenzene (-162.9 ppm) as external references. Elemental analyses were performed by the Perkin Elmer PE 2400.

Preparation of $\mathbf{C}_{\mathbf{8}} \mathbf{F}_{17} \mathbf{S O}_{3} \mathrm{Ag}$ (AgPFOS): ${ }^{\text {s1 }}$ Commercially available $\mathrm{C}_{8} \mathrm{~F}_{17} \mathrm{SO}_{3} \mathrm{H}$ was not pure, but used as received. A suspension of $\mathrm{C}_{8} \mathrm{~F}_{17} \mathrm{SO}_{3} \mathrm{H}(1.00 \mathrm{~g}$; assuming it was pure, it corresponded to $2.0 \mathrm{mmol})$ and $\mathrm{Ag}_{2} \mathrm{CO}_{3}(331 \mathrm{mg}, 1.2 \mathrm{mmol})$ in water $(15 \mathrm{~mL})$ was stirred in the dark at $100{ }^{\circ} \mathrm{C}$ for $1 \mathrm{~h}$, and then, at $\mathrm{rt}$ for $1 \mathrm{~h}$. After filtration, the solids obtained were washed with ice-water till the filtrate turned neutral. The solids were dissolved in acetone and filtered. After the filtrate had been evaporated, the crude solids were subjected to recrystallization from THF $(1.5 \mathrm{~mL})$ and $\mathrm{Et}_{2} \mathrm{O}(4 \mathrm{~mL})$ to afford $\mathrm{C}_{8} \mathrm{~F}_{17} \mathrm{SO}_{3} \mathrm{Ag}$ in a pure form (484 mg, 40\%). ${ }^{19} \mathrm{~F}$ NMR (282 MHz, acetone- $\left.d_{6}\right) \delta-79.20$ (m, 3F), -112.29 (m, 2F), -118.59 (m, 2F), -119.90 (m, 6F), -120.85 (m, 2F), -124.33 (m, 2F).

Preparation of $\left[(\mathrm{PFOS})\left(\mathrm{C}_{6} \mathrm{~F}_{13} \mathrm{C}_{2} \mathrm{H}_{4}\right)_{2} \operatorname{SnOSn}\left(\mathrm{C}_{2} \mathrm{H}_{4} \mathrm{C}_{6} \mathrm{~F}_{13}\right)_{2}(\mathrm{PFOS})\right]_{2} \cdot 10 \mathrm{H}_{2} \mathrm{O}$ ( 2•hydrate ): To an acetone solution (3 $\mathrm{mL}$ ) of $\left[(\mathrm{Cl})\left(\mathrm{C}_{6} \mathrm{~F}_{13} \mathrm{C}_{2} \mathrm{H}_{4}\right)_{2} \mathrm{SnOSn}\left(\mathrm{C}_{2} \mathrm{H}_{4} \mathrm{C}_{6} \mathrm{~F}_{13}\right)_{2}(\mathrm{Cl})\right]_{2}^{\mathrm{S} 2}(1.03 \mathrm{~g}, 0.3 \mathrm{mmol})$ was added an acetone solution $(2 \mathrm{~mL})$ of silver perfluorooctanesulfonate $(728 \mathrm{mg}, 1.2 \mathrm{mmol})$, and the mixture was stirred at $\mathrm{rt}$ for $1 \mathrm{~h}$ in the dark. After filtration, the filtrate was evaporated. To the crude products were added acetone $(2 \mathrm{ml})$ and FC-72 $(6 \mathrm{~mL})$, and the mixture was vigorously shaken. After the FC layer had been separated from the acetone layer, 
the FC layer was kept open to air at rt overnight to afforded $\mathbf{2}$ as a hydrate $(1.31 \mathrm{~g}, 80 \%$ calculated as decahydrate). Mp. $103-108{ }^{\circ} \mathrm{C}:{ }^{1} \mathrm{H}$ NMR (300 $\mathrm{MHz}$, acetone- $d_{6}$ ) $\delta$ 2.07 2.13 (m, 4H), 2.73 2.86 (m, 4H); ${ }^{19} \mathrm{~F}$ NMR (282 MHz, acetone- $\left.d_{6}\right) \delta-79.28$ (m, 18F), -112.28 (m, 4F), -114.66 (m, 8F), -118.72 (m, 4F), -120.20 (m, 20F), -121.30 (m, 20F), -124.55 (m, 12F); ${ }^{119} \mathrm{Sn}$ NMR (111 MHz, acetone- $\left.d_{6}\right) \delta$-241.7, -295.9. Anal. Calcd for $\mathrm{C}_{96} \mathrm{H}_{52} \mathrm{~F}_{172} \mathrm{O}_{24} \mathrm{~S}_{4} \mathrm{Sn}_{4}$ (as decahydrate): C, 21.12; H, 0.96. Found: C, 21.11; H, 0.88 .

Preparation of $\mathbf{H N}\left(\mathrm{SO}_{2} \mathrm{C}_{\mathbf{8}} \mathbf{F}_{17}\right)_{2}$ (PFOSA): To a methanol solution (50 mL) of $\left(\mathrm{C}_{8} \mathrm{~F}_{17}\right.$ $\left.\mathrm{SO}_{2}\right)_{2} \mathrm{NK}^{\mathrm{S} 3}(2.55 \mathrm{~g}, 2.5 \mathrm{mmol})$ was added Nafion NR50 (8.75 g), and the mixture was heated at $50{ }^{\circ} \mathrm{C}$ for $12 \mathrm{~h}$. After the mixture had been filtered, a filtrate was evaporated. The residue was subjected to sublimation $\left(170{ }^{\circ} \mathrm{C} / 1.0 \mathrm{mmHg}\right)$ to afford $\mathrm{HN}\left(\mathrm{SO}_{2} \mathrm{C}_{8} \mathrm{~F}_{17}\right)_{2}$ in a pure form $(1.42 \mathrm{~g}, 58 \%) .{ }^{1} \mathrm{H}$ NMR $\left(300 \mathrm{MHz}\right.$ acetone- $\left.d_{6}\right) \delta 2.07(\mathrm{~s}, 1 \mathrm{H}) ;{ }^{19} \mathrm{~F}$ NMR (282 MHz, acetone- $\left.d_{6}\right) \delta-79.35(\mathrm{~m}, 6 \mathrm{~F}),-112.99(\mathrm{~m}, 4 \mathrm{~F}),-118.85(\mathrm{~m}, 4 \mathrm{~F}),-$ 119.90 (m, 12F), -120.95 (m, 4F), -124.43 (m, 4F).

Preparation of $\operatorname{AgN}\left(\mathrm{SO}_{2} \mathrm{C}_{\mathbf{8}} \mathbf{F}_{17}\right)_{2}$ (AgPFOSA): To a water solution (15 mL) of $\left(\mathrm{C}_{8} \mathrm{~F}_{17} \mathrm{SO}_{2}\right)_{2} \mathrm{NH}$ was added $\mathrm{Ag}_{2} \mathrm{CO}_{3}(331 \mathrm{mg}, 1.2 \mathrm{mmol})$, and the mixture was stirred at $65^{\circ} \mathrm{C}$ for $6 \mathrm{~h}$ and at $\mathrm{rt}$ for $1 \mathrm{~h}$. After ice-water had been added to the mixture, the mixture was filtered and the obtained solids were washed with ice-water till the filtrate became neutral. The obtained solids were dissolved in acetone, and the solution was filtered. After the filtrate had been evaporated, the residue was subjected to recrystallization from $\mathrm{THF}(1.5 \mathrm{~mL}) / \mathrm{Et}_{2} \mathrm{O}(4.0 \mathrm{~mL})$ to afford AgPFOSA in a pure form (916 mg, 42\%). ${ }^{19} \mathrm{~F}$ NMR (282 MHz, acetone- $\left.d_{6}\right) \delta-79.18(\mathrm{~m}, 6 \mathrm{~F}),-112.30(\mathrm{~m}, 4 \mathrm{~F}),-$ $118.55(\mathrm{~m}, 4 \mathrm{~F}),-119.90(\mathrm{~m}, 12 \mathrm{~F}),-120.80(\mathrm{~m}, 4 \mathrm{~F}),-124.24(\mathrm{~m}, 4 \mathrm{~F})$.

\section{Preparation of $\left[(\mathrm{Cl})\left(\mathrm{C}_{6} \mathrm{~F}_{13} \mathrm{C}_{2} \mathrm{H}_{4}\right)_{2} \operatorname{SnOSn}\left(\mathrm{C}_{2} \mathrm{H}_{4} \mathrm{C}_{6} \mathrm{~F}_{13}\right)_{2}(\mathrm{PFOSA})\right]_{2} \cdot 11 \mathrm{H}_{2} \mathrm{O}$} ( 3.hy d rat e ): To an acetone solution ( $3 \mathrm{~mL})$ of $\left[(\mathrm{Cl})\left(\mathrm{C}_{6} \mathrm{~F}_{13} \mathrm{C}_{2} \mathrm{H}_{4}\right)_{2} \mathrm{SnOSn}\left(\mathrm{C}_{2} \mathrm{H}_{4} \mathrm{C}_{6} \mathrm{~F}_{13}\right)_{2}(\mathrm{Cl})\right]_{2}(1.03 \mathrm{~g}, 0.3 \mathrm{mmol})$ was added an acetone solution (2 mL) of $\mathrm{AgN}\left(\mathrm{SO}_{2} \mathrm{C}_{8} \mathrm{~F}_{17}\right)_{2}(653 \mathrm{mg}, 0.6 \mathrm{mmol})$, and the mixture was stirred at $\mathrm{rt}$ for $1 \mathrm{~h}$ in the dark. After filtration, the filtrate was evaporated. To the crude products were added acetone $(2 \mathrm{~mL})$ and FC-72 $(6 \mathrm{~mL})$, and the mixture was vigorously shaken. After the FC layer had been separated from the acetone layer, the FC layer was kept open to air at $\mathrm{rt}$ overnight to afforded $\mathbf{3}$ as a hydrate $(1.32 \mathrm{~g}, 80 \%$ calculated as undecahydrate). Mp. 85-90 ${ }^{\circ} \mathrm{C}:{ }^{1} \mathrm{H}$ NMR $\left(300 \mathrm{MHz}\right.$, acetone- $\left.d_{6}\right) \delta 2.04-2.10(\mathrm{~m}, 8 \mathrm{H})$, 2.69-2.87 (m, 8H); ${ }^{19} \mathrm{~F}$ NMR (282 MHz, acetone- $\left.d_{6}\right) \delta-79.4(\mathrm{~m}, 36 \mathrm{~F}),-112.12(\mathrm{~m}, 8 \mathrm{~F})$, -114.65 (m, 16F), -118.70 (m, 8F), -120.15 (m, 40F), -121.29 (m, 40F), -124.50 (m, 24F); ${ }^{119} \mathrm{Sn}$ NMR $\left(111 \mathrm{MHz}\right.$, acetone- $\left.d_{6}\right) \delta-240.5,-293.5$. Anal. Calcd for 
$\mathrm{C}_{96} \mathrm{H}_{54} \mathrm{Cl}_{2} \mathrm{~F}_{172} \mathrm{~N}_{2} \mathrm{O}_{21} \mathrm{~S}_{4} \mathrm{Sn}_{4}$ (as undecahydrate): C, 20.91; H, 0.99. Found: C, 21.30; H, 0.88 .

Determination of hydration number of 2•hydrate (representative): MS 4A (11 g, dried at $190{ }^{\circ} \mathrm{C}$ for $0.5 \mathrm{~h}$ under reduced pressure) was added to acetone- $d_{6}(25 \mathrm{~g})$, and the mixture was kept under argon overnight. To this acetone- $d_{6}(1.0 \mathrm{~mL})$ was added $\mathrm{CF}_{3} \mathrm{C}_{6} \mathrm{H}_{5}(146.1 \mathrm{mg}, 1.0 \mathrm{mmol})$, and the solution was analyzed by ${ }^{1} \mathrm{H}$ NMR. Integrations were calibrated on the basis of $\mathrm{C}_{6} \mathrm{H}_{5}$ of $\mathrm{CF}_{3} \mathrm{C}_{6} \mathrm{H}_{5}(\delta 7.42 \sim 7.69,5 \mathrm{H})$, and two protons of water were observed at $3.46 \mathrm{ppm}$ as $0.03 \mathrm{H}$ of singlet. To this dehydrated acetone- $d_{6}(0.7 \mathrm{~mL})$ was added $\mathbf{2} \bullet$ hydrate $(10.0 \mathrm{mg}$, recrystallized from FC72 as described above, dried under reduced pressure for $1 \mathrm{~h}$ and kept in open air for 10 days), and the solution was analyzed by ${ }^{1} \mathrm{H}$ NMR. Based on integrations of $\mathrm{C}_{2} \mathrm{H}_{4}$ of 2 ( $\delta$ 2.07 2.13, 2.73 2.86, m, 0.35H observed for $32 \mathrm{H}$ ) and $\mathrm{H}_{2} \mathrm{O}(\delta 3.56, \mathrm{~s}, 0.20 \mathrm{H}$ observed for $2 \mathrm{H}$ ), the hydration number was determined to be 2.3 per each $\mathrm{Sn}$ atom.

According to the same procedure, hydration number of $\mathbf{3} \cdot \mathbf{h y d r a t e}$ was determined to be 2.7 per each Sn atom. The compound was not soluble in hot FC-72. Dehydration of 2•hydrate was not feasible by azeotropic distillation with other solvents.

Determination of solubility of $2 \bullet$ hydrate (representative): To a test tube was added EtOAc $(0.5 \mathrm{~mL})$, and $\mathbf{2} \cdot \mathbf{h y d r a t e}$ was added gradually at $\mathrm{rt}$. When the amount of added $\mathbf{2} \cdot$ hydrate exceeded $164.8 \mathrm{mg}$, insoluble $\mathbf{2} \cdot \mathbf{h y d r a t e}$ appeared. Based on this datum, the solubility of $\mathbf{2} \cdot \mathbf{h y d r a t e}$ was determined to be $6.25 \times 10^{-2} \mathrm{mmol} / \mathrm{mL}$. According to the same procedure, other solubilities were determined.

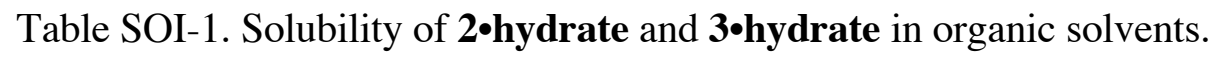

\begin{tabular}{lcc}
\hline & \multicolumn{2}{c}{ solubility $(\mathrm{mmol} / \mathrm{mL})$} \\
\cline { 2 - 3 } organic solvent & $\mathbf{2 \bullet h y d r a t e}$ & 3•hydrate \\
\hline $\mathrm{CH}_{3} \mathrm{CN}$ & $2.54 \times 10^{-4}$ & $\mathrm{~ns}^{a}$ \\
EtOAc & $6.25 \times 10^{-2 b}$ & $6.21 \times 10^{-2 c}$ \\
Acetone & $4.73 \times 10^{-2}$ & $9.41 \times 10^{-2}$ \\
THF & $3.79 \times 10^{-2}$ & $6.21 \times 10^{-2}$ \\
$\mathrm{MeOH}$ & $1.46 \times 10^{-2}$ & $3.76 \times 10^{-2}$ \\
\hline
\end{tabular}

${ }^{a}$ Not soluble. ${ }^{b}$ Amounts to $330 \mathrm{mg} .{ }^{c}$ Amounts to $331 \mathrm{mg}$. 


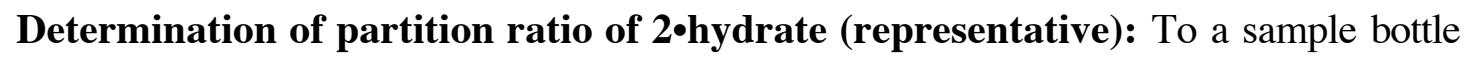
were added 2•hydrate $(100.0 \mathrm{mg})$, EtOAc $(2.0 \mathrm{~mL})$ and FC-72 $(2.0 \mathrm{~mL})$ at $\mathrm{rt}$, and 2•hydrate was dissolved completely. These two layers were transferred separately to round-bottomed flasks by pipettes. Trifluoromethylbenzene $(146.1 \mathrm{mg}, 1.0 \mathrm{mmol})$ was added to $1.0 \mathrm{~mL}$ of the FC-72 layer, and the solution was analyzed by ${ }^{1} \mathrm{H}$ NMR in $\mathrm{CDCl}_{3}$. When integration was calibrated on the basis of $\mathrm{C}_{6} \mathrm{H}_{5}$ of $\mathrm{CF}_{3} \mathrm{C}_{6} \mathrm{H}_{5}$ ( $\delta$ 7.42 7.69, 5H), 16 protons of $\mathrm{CF}_{2}-\mathrm{CH}_{2}$ of $2 \cdot \mathbf{h y d r a t e}$ were observed at $2.9 \mathrm{ppm}$ as $0.147 \mathrm{H}$ of broad singlet, and 2 protons of $\mathrm{CH}_{2}$ of EtOAc were observed at $4.2 \mathrm{ppm}$ as $1.542 \mathrm{H}$ of quartet. Based on these integrations, concentrations of $\mathbf{2} \cdot \mathbf{h y d}$ drate and EtOAc in FC-72 were determined to be $9.18 \times 10^{-3} \mathrm{mmol} / \mathrm{mL}$ and $7.71 \times 10^{-1} \mathrm{mmol} / \mathrm{mL}$, respectively. After evaporation of each layer, $92.7 \mathrm{mg}$ of $\mathbf{2} \cdot \mathbf{h y y d r a t e}$ was recovered from FC-72, and $6.6 \mathrm{mg}$ of $\mathbf{2} \bullet$ hydrate was recovered from EtOAc. Based on these data, partition of 2•hydrate between FC-72 and EtOAc was determined to be 93:7. According to the same procedure, other partitions were determined.

Table SOI-2. Partition of $\mathbf{2}$ between fluorocarbon and organic solvent. ${ }^{a}$

fluorocarbon $\quad$ organic solvent partition $^{b}$

FC-77

$\mathrm{CH}_{3} \mathrm{CN} \quad 94: 6$

FC-77

EtOAc 93:7

Perfluoromethylcyclohexane

$\mathrm{CH}_{3} \mathrm{CN} \quad 95: 5$

Perfluoromethylcyclohexane

EtOAc $\quad 92: 8$

\footnotetext{
${ }^{a} \mathbf{2} \bullet$ hydrate $(100 \mathrm{mg})$ in fluorocarbon $(2 \mathrm{~mL})$ /organic solvent $(2 \mathrm{~mL})$.

${ }^{b}$ Determined by isolation of $\mathbf{2}$ from the respective layers.
}

Solubility determination of $2 \cdot$ hydrate in a mixture of fluorous and organic solvents (representative): To a test tube were added $\mathbf{2} \bullet \mathbf{h y d r a t e}(300 \mathrm{mg}$ ) and acetone (dried from $\mathrm{CaH}_{2}, 3.0 \mathrm{~mL}$ ), and $\mathbf{2} \bullet \mathbf{h y d}$ drate was dissolved in acetone. To the solution was added FC-72 by a syringe, and the mixture was stirred vigorously. When $87.2 \mathrm{~mL}$ of FC-72 was added, the mixture turned a homogeneous solution. Based on this data, the maximum amount of acetone to be dissolved in $100 \mathrm{~mL}$ of FC-72 in the presence of $300 \mathrm{mg}$ of $\mathbf{2} \cdot \mathbf{h y d r a t e}$ was determined to be $3.44 \mathrm{~mL}$. According to the same procedure, other partitions were determined to give Figure (a). This Figure was converted to Figure (b), the ordinate of which corresponds to the maximum amounts of EtOAc that can be dissolved in $100 \mathrm{~mL}$ of FC-72 at various levels of distannoxane concentration. 

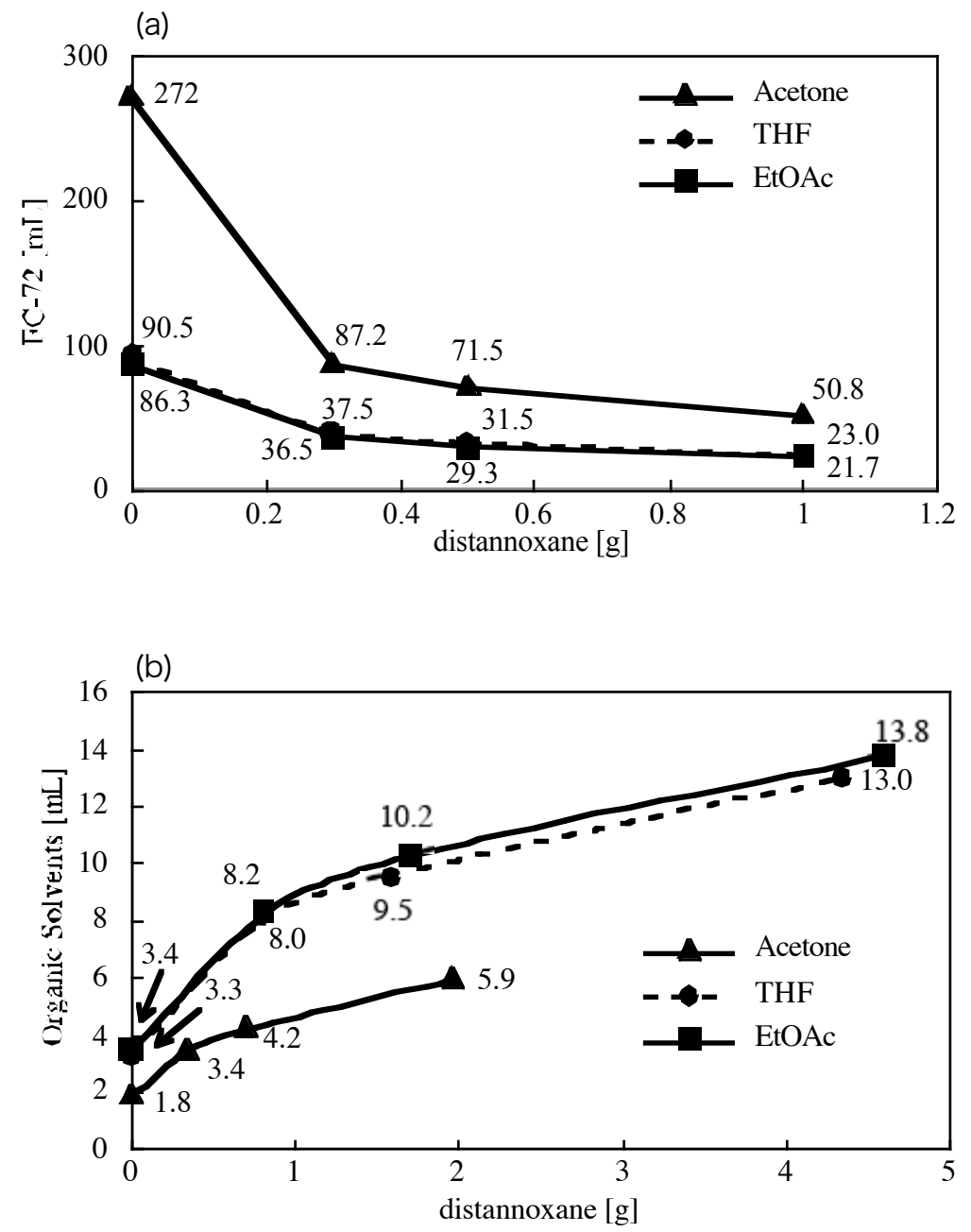

(a) The amount of FC-72 required for obtaining a homogeneous solution with organic solvent ( $3 \mathrm{~mL}$ ) containing various amount of $\mathbf{2} \cdot$ hydrate. (b) The maximum amount of organic solvent to be dissolved in $100 \mathrm{~mL}$ of FC-72 versus concentration of 2•hydrate.

[S-1] G.M. Whitesides, F.D. Gutowski, J. Org. Chem. 1976, 41, 2882.

[S-2] J. Xiang, A. Orita, J. Otera, J. Organomet. Chem. 2002, 648, 246.

[S-3] K.Sogabe, Y. Hasegawa, Y. Wada, T. Kitamura, S. Yanagiba, Chem. Lett. 2000, 944. 
